\title{
Increased Risk of Cutaneous Diseases in Multiple Myeloma Patients
}

\author{
Talayesa Buntinx-Krieg ${ }^{1}$, Ryan M. McKee ${ }^{1}$, Dawn Z. Eichenfield ${ }^{1}$, Amanda Marsch ${ }^{1}$ \\ 1. Department of Dermatology, University of California San Diego, La Jolla, USA
}

Corresponding author: Ryan M. McKee, rmmckee@health.ucsd.edu

\section{Abstract \\ Introduction}

Multiple myeloma (MM) is a monoclonal gammopathy characterized by malignant proliferation of plasma cells in the bone marrow, leading to the overproduction of monoclonal immunoglobulins. Knowledge of cutaneous findings associated with multiple myeloma is limited. This study aims to characterize cutaneous manifestations in patients with MM or monoclonal gammopathy of undetermined significance (MGUS).

\section{Methods}

This is a retrospective study of patients seen at a single institution between January 2000 and January 2019 with a diagnosis of "multiple myeloma," "monoclonal gammopathy of undetermined significance," or "smoldering myeloma," and an on-site dermatology clinic visit.

\section{Results}

Twenty patients met the inclusion criteria. Most patients were male and Caucasian. Comorbid cutaneous malignancies were noted in $65 \%$ of patients $(n=13)$. Basal cell carcinoma $(B C C)$ was characterized in $55 \%$ of patients $(n=11)$, followed by squamous cell carcinoma in $50 \%$ of patients $(n=10)$, and melanoma in $10 \%$ of patients $(n=2)$.

\section{Conclusions}

Patients with monoclonal gammopathy may be predisposed to developing cutaneous malignancies and skin infections. Given the low prevalence of monoclonal gammopathy, larger multi-center studies with a control cohort may be necessary to delineate the significance of these comorbid skin conditions.

Received 05/03/2020

Review began 05/07/2020 Review ended 09/01/2020 Published 09/10/2020

\section{(c) Copyright 2020}

Buntinx-Krieg et al. This is an open access article distributed under the terms of the Creative Commons Attribution License CC-BY 4.0., which permits unrestricted use, distribution, and reproduction in any medium, provided the original author and source are credited.
Categories: Dermatology, Oncology

Keywords: multiple myeloma, myeloma of undetermined significance, skin conditions, oncology, monoclonal gammopathy

\section{Introduction}

Although multiple myeloma (MM) is an uncommon disease with a lifetime risk of 1 in 132 in the United States [1], recent advances in MM treatment have prolonged survival and led to an increased disease prevalence. Cutaneous involvement in MM most commonly results from metastasis and direct extension of disease from nearby tumor foci, presenting as palpable violaceous nodules on the trunk and extremities [2]. A recent Korean case series of 1,228 patients reported direct cutaneous involvement in only $1.14 \%$ of patients with MM. Direct cutaneous involvement was associated with significantly reduced overall survival in patients with MM [2]. Skin diseases associated with MM have been classified as specific and non-specific. The term "monoclonal gammopathy of cutaneous significance" was coined to describe dermatologic conditions strongly associated with a monoclonal gammopathy. Some examples of monoclonal gammopathy of cutaneous significance include purpura, hemorrhagic bullae, and macroglossia [3]. In contrast, the nonspecific cutaneous findings associated with MM have not been well-established. One group did recently report a case series of four patients presenting with cutaneous manifestations such as leukocytoclastic vasculitis, pyoderma gangrenosum, and vesiculobullous disorders who were subsequently diagnosed with MM [4]. More recently, the International Myeloma Working Group has identified an increased risk of second primary malignancies in MM patients [5]. As such, a better understanding of cutaneous manifestations associated with MM could aid in earlier diagnosis of MM and be of prognostic significance. Here, we provide a retrospective review of patients with monoclonal gammopathy and analyze their associated cutaneous manifestations.

\section{Materials And Methods}

This is a retrospective analysis of patients diagnosed with monoclonal gammopathy between January 2000 and January 2019 at a single academic institution. Patients were identified using the following diagnoses: "multiple myeloma," "monoclonal gammopathy of undetermined significance," or "smoldering 


\section{Cureus}

myeloma,” ICD-10 codes: C90.01, C90.00, D47.2 and ICD-9 codes: 203.0, 273.1. All patients ages 18-100 years who had visit(s) to an on-site dermatology clinic between January 2000 and January 2019 were included in the analysis. Twenty patients met the inclusion criteria. Chart review took place between November 1, 2019 and January 31, 2020, and de-identified data were imported into Microsoft Excel for analysis.

\section{Results}

The majority of patients included in the analysis were male (12/20) and Caucasian (16/20). Thirteen patients were diagnosed with MM while seven patients had a diagnosis of MGUS. Patient characteristics are outlined in Table 1. As expected in an older cohort, most patients had also received a diagnosis of skin cancer (13/20) (Table 2). Basal cell carcinoma (BCC) was seen in 11/20 patients, while cutaneous squamous cell carcinoma and melanoma were diagnosed in $10 / 20$ and 2/20 patients, respectively (Table 2). Several patients (8/20) had been diagnosed with both BCC and squamous cell carcinoma (SCC). Interestingly, two of three patients in our cohort with graft-versus-host disease (GVHD) eventually developed skin cancer, specifically BCC; however, none of the GVHD patients developed SCC.

A high number of infections were also observed in this cohort $(17 / 20)$, which included skin infections $(\mathrm{n}=$ $17)$, urinary tract infections $(n=15)$, bacteremia $(n=13)$, upper respiratory tract infections $(n=8)$, and systemic viral infections $(\mathrm{n}=4$; Table 1$)$. A number of other cutaneous conditions were observed in a minority of patients, which have been reported to aid in future studies (Table 1). Most patients received treatment for their plasma cell dyscrasia (13/20), which included allogeneic and autologous bone marrow transplantation $(n=8)$, lenalidomide $(n=12)$, dexamethasone $(n=10)$, bortezomib $(n=9)$, thalidomide $(n=$ 6), and rituximab ( $n=2$; Table 1$)$. Regarding treatment complications, drug-induced pancytopenia was most commonly reported $(n=7)$, followed by drug-induced neuropathy $(n=5)$, then GVHD $(n=3)$, and adrenal insufficiency $(\mathrm{n}=3$; Table 1$)$.

Patient characteristics

Number

Mean age \pm standard deviation, years

Age range, years

Mean age at myeloma diagnosis \pm standard deviation, years

Age range at myeloma diagnosis, years

Male

Female

Ethnicity

Caucasian

Hispanic

Other

$1(5)$

Myeloma characteristics

Diagnosis

MM

MGUS

Immunoglobulin subtype

IgA kappa

IgG kappa

IgG lambda

$\lg \mathrm{D}$ kappa 


\section{Cureus}

Unknown

Other cancer diagnoses

Prostate cancer

Lung cancer

Bladder cancer

Renal cell carcinoma

Endometrial cancer

Acute myeloid leukemia

Mycosis fungoides

Gallbladder cancer

Benign tumors

Benign sebaceous tumors

Acantholytic acanthoma

BRCA1-associated-protein-oma

Cutaneous diseases

Dermatomyositis

Leukocytic vasculitis

Mycosis fungoides (folliculotropic)

Neutrophilic urticarial dermatosis

Psoriasis

Stasis dermatitis

Stasis ulcer

Porokeratosis

Folliculitis

Chronic GVHD

Acute GVHD

Vulvar dysplasia

Cellulitis

Seborrheic dermatitis

Xerosis

Hypertrophic scars

Lymphedema

Lipodermatosclerosis

Skin infections

Escherichia coli 


\section{Cureus}

Dermabacter hominis

Herpes simplex virus $3(15)$

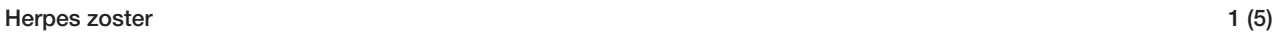

Unknown 1 (5)

Urinary tract infections

E. coli $6(30)$

$\begin{array}{ll}\text { P. aeruginosa } & 2(10)\end{array}$

Citrobacter koseri $\quad 2(10)$

Proteus mirabilis $3(15)$

$\begin{array}{ll}\text { Klebsiella } & 2(10)\end{array}$

Bacteremia

$\begin{array}{ll}\text { E. coli } & 4(20)\end{array}$

$\begin{array}{ll}\text { Methicillin-sensitive S. aureus } & 4(20)\end{array}$

$\begin{array}{ll}\text { Citrobacter } & 1(5)\end{array}$

Klebsiella 1 (5)

Methicillin-resistant S. aureus $\quad 1(5)$

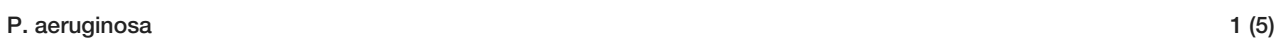

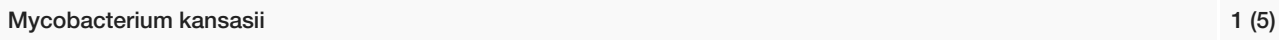

Upper respiratory tract infections

$\begin{array}{ll}\text { Candida albicans } & 2(10)\end{array}$

$\begin{array}{ll}\text { P. aeruginosa } & 2(10)\end{array}$

Streptococcus 1 (5)

$\begin{array}{ll}\text { Aspergillus } & 1(5)\end{array}$

Klebsiella $2(10)$

Viral infections

Disseminated herpes simplex virus 1 (5)

Human herpes virus-6 reactivation $\quad 1$ (5)

Epstein Barr virus reactivation $\quad 1$ (5)

Disseminated cytomegalovirus $\quad 1$ (5)

Myeloma treatment medications

$\begin{array}{lc}\text { Ixazomib } & 3(15) \\ \text { Dexamethasone } & 10(50) \\ \text { Lenalidomide } & 12(60) \\ \text { Bortezomib } & 9(45) \\ \text { Anakinra } & 1(5) \\ \text { Rituximab } & 2(10) \\ \text { Pomalidomide } & 5(25) \\ \text { Carfilzomib } & 2(10) \\ \text { Cyclophosphamide } & 1(5)\end{array}$




\section{Cureus}

Elotuzumab $2(10)$

$\begin{array}{lr}\text { Thalidomide } & 6(30)\end{array}$

$\begin{array}{lr}\text { Biaxin } & 1(5)\end{array}$

$\begin{array}{lr}\text { Vincristine } & 1(5)\end{array}$

$\begin{array}{lr}\text { Doxorubicin } & 1(5)\end{array}$

Bone marrow transplant - autologous $\quad 5(25)$

Bone marrow transplant - allogeneic $3(15)$

Myeloma treatment complications

$\begin{array}{ll}\text { Adrenal insufficiency } & 3(15)\end{array}$

$\begin{array}{ll}\text { GVHD } & 3(15)\end{array}$

$\begin{array}{ll}\text { Drug-induced neuropathy } & 5(25)\end{array}$

$\begin{array}{ll}\text { Drug-induced pancytopenia } & 7(35)\end{array}$

Drug-induced rash $1(5)$

$\begin{array}{lr}\text { Acute myeloid leukemia } & 1(5)\end{array}$

$\begin{array}{lr}\text { Drug-induced pneumonitis } & 1(5)\end{array}$

\section{TABLE 1: MM patient characteristics}

SD: standard deviation, BAPoma: BRCA1-associated-protein-oma, MM: multiple myeloma, MGUS: monoclonal gammopathy of undetermined significance, GVHD: graft-versus-host disease. 


\section{Cureus}

Skin Cancer Characteristics

Value (\%)

Number of patients

$13(65)$

BCC

$11(55)$

Total number of lesions

26

Mean number of lesions per patient

Subtype prevalence (number of lesions)

Nodular

9

Superficial

6

Basosquamous

1

Pigmented

Micronodular

Unknown

3

SCC

Total number of lesions

Mean number of lesions per patient

Subtype prevalence (number of lesions)

Bowen's disease

Invasive squamous cell carcinoma

Keratoacanthoma

Melanoma

Total number of lesions

Subtype prevalence (number of lesions)

Lentigo maligna

\section{TABLE 2: Skin cancers in patients with MM}

MM: multiple myeloma, BCC: basal cell carcinoma, SCC: squamous cell carcinoma.

\section{Discussion}

Although our cohort was smaller than some previously published studies, our results recapitulated those of prior larger cohort studies [2]. For example, similar to previous studies, our analysis also found IgG as the most common heavy chain subtype, followed by IgA [2]; however, in contrast to prior studies where the most commonly reported light chain was lambda, the most common light chain in our population was kappa.

While it may be difficult to draw definitive conclusions given our small patient population and lack of a control group, comorbid cutaneous malignancies (predominantly non-melanoma skin cancer) and infections appeared to be highly prevalent in this cohort. Caucasians have been reported to have a higher incidence of non-melanoma skin cancer than African Americans, while African Americans carry a twofold to threefold higher rate of MM than Caucasians [6]. Since $80 \%$ of our cohort was Caucasian, the higher rate of skin cancer noted here may not be applicable to a predominantly African American cohort. Therefore, it would be interesting to investigate the rates of skin cancer in a larger cohort with a higher percentage of African American patients.

Although more patients were diagnosed with BCC than SCC, SCC (30 Bowen's disease lesions and 22 invasive SCC lesions) was the most commonly observed non-melanoma skin cancer in our cohort (56 SCCs compared to 26 BCCs total, Table 2). We suspect these findings are due to the impaired immune function 
inherent in MM patients, and may also be sequelae of MM therapies. These results are similar to those published in a recent large retrospective cohort study of $205 \mathrm{MM}$ patients and 193 controls, which also demonstrated an increased incidence of skin cancer in MM patients ( $26.8 \%$ vs. $16.1 \%$ in controls; $\mathrm{P}=0.009)$ [7]. Furthermore, immune dysfunction may also explain the high number of infections observed in our study; however, a larger retrospective cohort study with controls is needed to definitively ascertain whether the presence of monoclonal gammopathy predisposes patients to more infections.

There are several limitations of our study, which include a small patient population at a single academic institution, the retrospective nature of chart review, a lack of a control population, and a dependence on electronic medical record coding to identify patients. Unfortunately, by including only patients seen by dermatology, a majority of patients with plasma cell dyscrasias were excluded from this study. This finding in itself highlights that patients with monoclonal gammopathy may not be obtaining the necessary cutaneous care that should be a part of their management regimen, given their high prevalence of bone marrow transplant and immunosuppression. Despite these limitations, our findings are similar to those previously published in larger retrospective studies and also add to the literature by providing new insight into the significance of infections in MM and MGUS patients.

\section{Conclusions}

MM is a rare disease characterized by the overproduction of monoclonal immunoglobulin. Despite being associated with significantly reduced overall survival, the cutaneous manifestations seen in patients with MM have not been thoroughly investigated. In this single institution retrospective review, we report a variety of comorbid skin findings in our cohort of patients with MM and MGUS. Of these, non-melanoma skin cancer and infections are especially prevalent, which may result from impaired immune defense in this patient population. Future studies are needed to further elucidate the diagnostic and prognostic significance of individual comorbid skin conditions in MM patients.

\section{Additional Information}

\section{Disclosures}

Human subjects: Consent was obtained by all participants in this study. UC San Diego Institutional Review Board issued approval 191226. Animal subjects: All authors have confirmed that this study did not involve animal subjects or tissue. Conflicts of interest: In compliance with the ICMJE uniform disclosure form, all authors declare the following: Payment/services info: All authors have declared that no financial support was received from any organization for the submitted work. Financial relationships: All authors have declared that they have no financial relationships at present or within the previous three years with any organizations that might have an interest in the submitted work. Other relationships: All authors have declared that there are no other relationships or activities that could appear to have influenced the submitted work.

\section{References}

1. Key statistics about multiple myeloma . (2020). Accessed: January 1, 2020: https://www.cancer.org/cancer/multiple-myeloma/about/key-statistics.html.

2. Woo YR, Kim JS, Lim JH, et al.: Prevalence and clinicopathologic characteristics of multiple myeloma with cutaneous involvement: a case series from korea. J Am Acad Dermatol. 2018, 78:471-478. 10.1016/j.jaad.2017.08.054

3. Lipsker D: Monoclonal gammopathy of cutaneous significance: review of a relevant concept . J Eur Acad Dermatol Venereol. 2017, 31:45-52. 10.1111/jdv.13847

4. Behera B, Pattnaik M, Sahu B, Mohanty P, Jena S, Mohapatra L: Cutaneous manifestations of multiple myeloma. Indian J Dermatol. 2016, 61:668-671. 10.4103/0019-5154.193682

5. Musto P, Anderson KC, Attal M, et al.: Second primary malignancies in multiple myeloma: an overview and IMWG consensus. Ann Oncol. 2017, 28:228-245. 10.1093/annonc/mdw606

6. Baughn LB, Pearce K, Larson D, et al.: Differences in genomic abnormalities among African individuals with monoclonal gammopathies using calculated ancestry. Blood Cancer J. 2018, 10:96. 10.1038/s41408-0180132-1

7. Robinson AA, Wang J, Vardanyan S, et al.: Risk of skin cancer in multiple myeloma patients: a retrospective cohort study. Eur J Haematol. 2016, 97:439-444. 10.1111/ejh.12748 